\title{
"Bath salts"
}

Tony Antoniou BScPhm PharmD, David N. Juurlink MD PhD

\section{"Bath salts" are not really bath salts}

Bath salts are synthetic derivatives of cathinone, a naturally occurring stimulant found in the khat plant (Catha edulis) of eastern Africa and the Arabian Peninsula. ${ }^{1,2}$ Although many cathinones have been synthesized for recreational use, mephedrone and 3,4-methylenedioxypyrovalerone (MDPV) account for most reports of toxicity. ${ }^{1,2}$ The most common routes of administration are nasal insufflation and oral ingestion. ${ }^{2,3}$ These drugs are commonly sold as white- or tan-coloured crystalline powders that are labelled as "bath salts" and marked as "not for human consumption" to avoid detection and regulation by authorities. ${ }^{1,2}$

Toxicity is consistent with a sympathomimetic toxidrome

Because synthetic cathinones are structurally and pharmacologically similar to amphetamines, adverse effects associated with these compounds resemble those of other sympathomimetics (Appendix 1, available at www.cmaj.ca/lookup/suppl /doi:10.1503/cmaj.121017/-/DC1)., ${ }^{1,2}$ The most common features of sympathomimetic toxicity seen among users of synthetic cathinones presenting to emergency departments were agitation (38.9\%), palpitations (25.0\%), hypertension (13.9\%) and tachycardia $(36.1 \%){ }^{2}$ Lifethreatening hyponatremia and hyperthermia are uncommon but have been associated with death. ${ }^{1,2}$

Because basic drug screens do not detect synthetic cathinones, a high index of suspicion for these compounds is required when evaluating patients showing signs of a sympathomimetic toxidrome with negative urine toxicology results. Some cathinones can be detected with chromatographic techniques. ${ }^{2}$

\section{Treatment is supportive}

No specific antidote exists for synthetic cathinone toxicity. ${ }^{1,2}$ Benzodiazepines are used to treat agitation, seizures and hypertension. ${ }^{1,2}$ Persistent hypertension should be managed with $\alpha$-adrenergic antagonists or peripheral vasodilators; $\beta$ adrenergic blockers should be avoided because they may intensify the stimulation of $\alpha$-receptors. ${ }^{1}$ Hyperthermia (a poor prognostic sign) warrants aggressive cooling. ${ }^{1}$ Hyponatremia will often respond to water restriction, although hypertonic saline may be required in severe cases complicated by seizures. ${ }^{1}$

\section{References}

1. Prosser JM, Nelson LS. The toxicology of bath salts: a review of synthetic cathinones. J Med Toxicol 2012;8:33-42.

2. Dargan PI, Sedefov R, Gallegos A, et al. The pharmacology and toxicology of the synthetic cathinone mephedrone (4-methylmethcathinone). Drug Test Anal 2011;3:454-63.

3. Winstock AR, Mitcheson LR, Deluca P, et al. Mephedrone, new kid for the chop? Addiction 2011; 106:154-61.

4. Barrick F. "Bath salts" drug has experts on high alert. GuelphMercury.com 2012 May 31. Available: www.guelphmercury.com/print/article /735655 (accessed 2012 July 26).

5. Winstock A, Mitcheson L, Ramsay J, et al. Mephedrone: use, subjective effects and health risks. Addiction 2011;106:1991-6.

\section{Use of synthetic cathinones is in- creasingly reported in Canada}

Although first reported by hospital emergency departments and withdrawal management centres in the Maritime provinces, the use of synthetic cathinones has recently been seen in other provinces. ${ }^{4}$ The desired effects of the drug include increased energy, sociability and libido. ${ }^{1,2}$ Coingestion of additional recreational drugs, such as $\gamma$-hydroxybutyrate, amphetamines or cocaine, is common. ${ }^{2}$

\section{Dependence and withdrawal can occur}

In a survey of people who use mephedrone, $44.3 \%$ described the drug as being at least as addictive as cocaine, and nasal insufflation was associated with more frequent use of larger amounts of the drug compared with oral ingestion. ${ }^{3}$ In another study, $22.4 \%$ of users of mephedrone reported strong cravings for continued use. ${ }^{5}$ Withdrawal symptoms after abruptly stopping use of the drug are rarely dangerous and include depression, anergia and drug craving. ${ }^{2.3}$

Competing interests: Tony Antoniou has received research grants from Merck and Pfizer. No other competing interests were declared.

This article has been peer reviewed.

Affiliations: From the Department of Family and Community Medicine (Antoniou), St. Michael's Hospital, Toronto, Ont.; Leslie Dan Faculty of Pharmacy (Antoniou), University of Toronto, Toronto, Ont.; Institute for Clinical Evaluative Sciences (Juurlink), Toronto, Ont.; and the Department of Medicine (Juurlink), Sunnybrook Health Sciences Centre, Toronto, Ont.

Correspondence to: Tony Antoniou, tantoniou @smh.ca

CMAJ 2012. DOI:10.1503/cmaj.121017 